\title{
Climate Change Adaptions for Urban Water Infrastructure in Jeddah, Kingdom of Saudi Arabia
}

\author{
Mohammed Aljoufie ${ }^{1} \&$ Alok Tiwari $^{1}$ \\ ${ }^{1}$ Department of Urban and Regional Planning, Faculty of Environmental Design, King Abdulaziz University, \\ Jeddah, Kingdom of Saudi Arabia \\ Correspondence: Mohammed Aljoufie, Department of Urban and Regional Planning, Faculty of Environmental \\ Design, King Abdulaziz University, Jeddah Postbox-80210, Kingdom of Saudi Arabia. Tel: 966-56-455-9133; \\ 966-59-475-1694. E-mail: maljufie@kau.edu.sa; atwari@kau.edu.sa
}

Received: January 13, 2015 Accepted: March 30, 2015 Online Published: May 28, 2015

doi:10.5539/jsd.v8n3p52 URL: http://dx.doi.org/10.5539/jsd.v8n3p52

\begin{abstract}
Cities play a crucial role in the planning of climate change adaptions. Although these actions are largely guided by global negotiations and national policies their consequences are usually felt by individual cities. Reconfiguring of urban infrastructure is the first step to ensure resilience to extreme weather events triggered by climate change. Many coastal cities are already begun to suffer because of climate change impacts; frequent flooding in Jeddah (Kingdom of Saudi Arabia) is an example. This paper attempts to investigate preparedness of urban water infrastructure in Jeddah for future climate change adaptions. It founds that the city has been lagging behind in action such as continuous \& consistent reporting of relevant data, capacity building, research, education and awareness building, reconfiguration and expansion of grey $\&$ green infrastructure. We propose to formulate a three point policy for climate change adaption at local level with proper attention to grey, green and soft infrastructures.
\end{abstract}

Keywords: climate change adaption, urban water infrastructure, grey infrastructure, green infrastructure, adaption policies, soft infrastructure, GHG emission, desalination

\section{Introduction}

\subsection{Climate Change and Urban Infrastructure}

Climate change is anticipated to accelerate average temperatures as well as to transform strength and occurrence of extreme precipitations (Cubasch et al., 2001) causing either overstress or total failure of urban infrastructures such as water supply and electricity that may transpire into loss of people's health, lives and property. Although body of knowledge on climate change is constantly growing worldwide, yet countries like Kingdom of Saudi Arabia-KSA has recently started, repositioning themselves towards climate change management (mitigation and adaption) strategies. This paper investigates resilience of urban water infrastructure towards climate change adaptions in KSA's second largest city Jeddah that is stressed with rapid urbanisation and population growth.

Researchers are already in agreement that larger human interferences are causing disruptions in climate and increasing the risks associated with climate change while constant GHG emissions will continue to produce furthermore warming and enduring changes in all constituents of climate system (UNEP, 2014). Though there are potential means to limit climate change, yet the same are tough to execute because of its complex causal nexus. One of the most visible effects of climate change could be seen in alteration of numerous eco-system services such as failure in accommodating climate calming could produce urban heat island effect (Zhou et.al. 2013); another impact of climate change argued to be higher uncertainty in rainfall pattern (Almazroui, 2012). While the Climate Change is triggering alterations in ecosystems two major strategies have been emerged as solution: Adaption and Mitigation; both are persuasive issues of concern the later must be synchronised worldwide, the earlier demands local actions (Sharp, 2011). In fact Integration of anticipated actions at various scales (global to local) creates hardships for climate change management.

Form of a society (from a hunting and gathering to agricultural and industrial) looks diligently connected to its energy uses in term of quality and quantity of energy. Because of development energy demands (for movement, cooling/heating and other consuming activities) in the society is growing in an accelerated way along with 
interactions (or interference). In fact our built infrastructure could be affected with climate change in a manner the society interacts with these infrastructures (Chappin \& Lei, 2014). Infrastructures are deliberated as complex socio-technical systems (Bruijn \& Herder, 2009) that manage flow of materials (land, water, air) in a society (Swilling et al., 2012). Furthermore this management of material flow calls for proper knowledge, resources and infrastructures.

Current pattern of economic activities is coupled with accelerated input of energy and materials leading to greater emissions that needed to be decoupled through reconfiguring of city's infrastructures (UNEP, 2013).Non infrastructural influential component of emission determinants could be our food habits, travelling behaviours, water consumptions and housing needs which are driven mainly by cultural, societal, economy and religious factors (Reusser et al., 2013).

Researchers perceive highly consuming urban lifestyles and higher car ownerships among other factors responsible for aggravated emissions. (Miles \& Miles, 2004; Minx et al., 2013). To obtain a better insight on the causes of GHG emissions through constant reporting is quite a tough task as the manuals for doing so calls for detailed inventory of technical descriptions (IPCC, 2006). The inherent notion beneath this computational structure is to calculate emissions at their generating sources; in other words it can be considered as location specific accounting. Conversely emissions might transpire at distant place of a good's production while the product is consumed at entirely different location. Hence by trading of consumer goods; emissions are transmitted worldwide virtually. Another concept has been emerged to rectify anomalies connected to above virtuality that is to account consumption based emission (Davis \& Caldeira, 2010) for which emissions caused in the production processes of a good is calculated for a nation where it is being consumed.

As negotiations on climate mitigations are part of international negotiations and treaties; policies are generally set at the national level yet hard infrastructure has been popularly accounted at the city levels in reference to emissions. Emissions through urban infrastructure are being calculated mostly based on their inventories (Dodman, 2009) which is either unorganised or absent in the most of the developing countries. Most recently C40Cities has accepted GPC (Global Protocol for Community-Scale Greenhouse Gas Emission Inventories) whose scope is divided into 3 major categories (i) GHG emission from the sources located inside the city boundaries (ii) GHG emission as a result of grid based energy uses (electricity, heat, cooling, steam). (iii)All GHG emissions; occurring outside the city boundaries; as a consequence of activities; within the city boundaries (WRI, 2014).

In general scholars are in agreement to accept climate change and acuteness of its impending impacts. It has been argued that climate change will not only reshape natural environment but it will also severely affect our infrastructure (VanVilet et al., 2012, Schweikert et al., 2014).There are firm evidences which asserts that extreme weather events are accelerating a far-reaching impact on urban systems in the last few decades (IPCC, 2007); floods in Jeddah and Morocco causing heavy destructions to urban infrastructures are some recent examples (Selvaraju, 2013).

UNFCC has recognizes two approaches to tackle climate change; first is mitigation of climate change by reduction in GHG emissions and augmenting carbon sinks, and the second adaptation to the impacts of climate change (IPCC, 2007). While it is really tough to determine which one of the both above mentioned approaches is more pertinent though scholars stresses to blend both of them thoughtfully into climate and development policies to create positive synergies (Klein et al., 2003).

Thus; research investigation on urban infrastructures are crucial because of 3 basic reasons: Firstly it prompts urban planners to focus on urban resource planning because infrastructure choices made at present will affects urban resource flows for decades to come (UNEP, 2013). Secondly these choices will also determine effect and magnitude of vulnerabilities or resilience of communities for Climate Change (OECD, 2014).Thirdly, as urban infrastructures are interconnected in nature vulnerability of one infrastructure affects the other infrastructure (Chappin \& Lei, 2014).

In fact Adaption to climatic fluctuation and climate change is not a new action for both natural and manmade systems; both attempt to adjust themselves for these changes from very ancient time; what has been changed is its magnitude and modus operandi.

\subsection{Research Questions}

This paper tries to find out replies of the following questions:

(i) Are there national policies supporting to global climate change negotiations?

(ii) How climate change could be evident at Jeddah city level? 
(iii) What is the current condition of urban water infrastructure in the city?

(iv) What the level of policy efficacy pertaining to the climate change adaption for urban water infrastructure.

\section{Methods, Materials and Study Area}

\subsection{Methods and Materials}

Descriptive research approach was deployed for the Case study of Jeddah in this paper. Both primary and secondary data were collected. Source of primary data was unstructured interviews; with Jeddah municipality official and experts; the secondary data sources include following:

- Grey literature mainly from National Water Company-NWC, Jeddah Business Unit-JBU, Jeddah Municipality and articles published in local newspaper (all in English).

- GIS data layers for urban water services coverage from Global Urban Observatory at Jeddah Municipality (with researcher updates).

Method of data analysis was mainly qualitative.

\subsection{Study Area}

Jeddah is an important strategic city in Kingdom of Saudi Arabia having second largest population in the country. It is legendary because of its identity as a gateway city through which Muslim pilgrims travelling to the holy city of Makkah for performing 'Hajj' or 'Ummarah' for centuries; apart from that that it is the most important sea port, airport and commercial city in the kingdom. Located at Red sea coast (Figure-1) in the western part of the country it is considered as most happening city in the country due to its cosmopolitan characteristics.

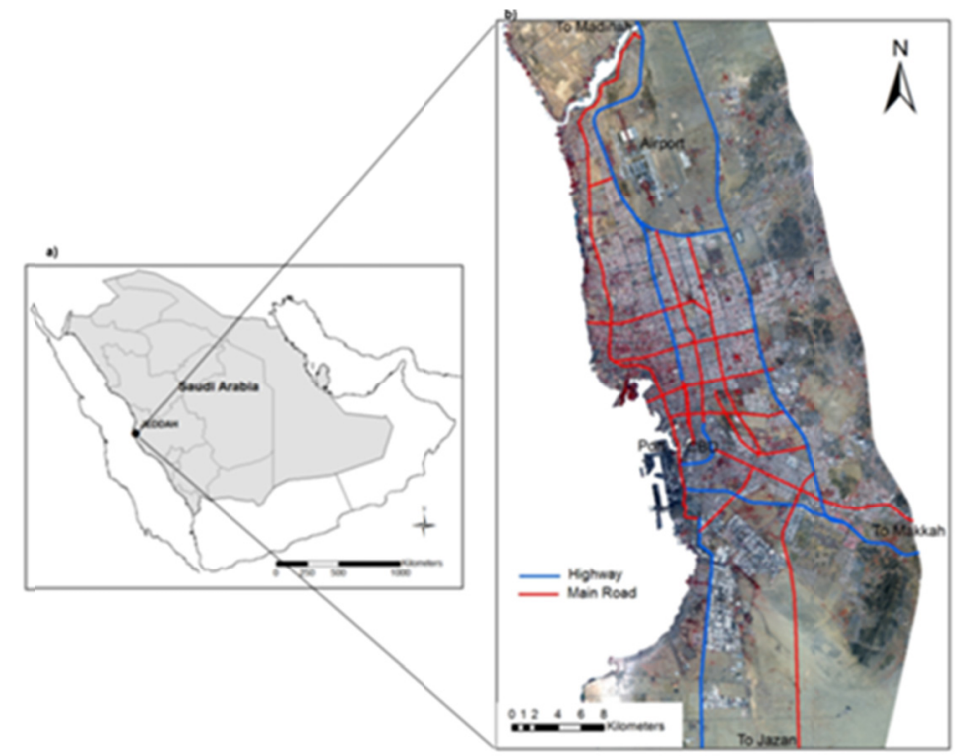

Figure 1. a) Geographic location of Jeddah b) Jeddah City

\section{Results and Discussion}

We argue that actions for climate change adaption at local level are driven by national level policies while the existing practices and scenario at local level determine the degree of infrastructure vulnerabilities. Thus this section in beginning examines national level preparations for climate change, later it scrutinise current ongoing practices in the city pertinent to city level climate change management and finally propose policy solutions.

\subsection{Climate Change Discourse in KSA}

Despite its progress in responding climate change (Darfaoui \& Al-Assiri, n.d) Saudi Arabia is often the most misunderstood nation in the climate change regime; it is believed that country's policies are against mitigations and adaptions to climate change that is a misconception.

In fact nation has its own anxiety on the issue, and before reaching upon an agreement on any climate change deal it seeks compensation in lieu of revenue loss for declining oil production (Vidal, 2010). Conversely experts has warned that KSA has no time to delay its action on climate change as simulations indicate that achieving energy efficiencies by 3 percent reduction from 2010-20 and 2 percent reduction from between 2021-30 could 
only arrange 5 years for transition towards lesser reliance upon oil exports and that is the time available for both strategies including economic diversification and the introduction of new technologies (Lahn \& Stevens, 2011).

Though contested and criticized because of its so called rigidity in international negotiations on climate change, KSA is attempting to reposition itself internally to play a positive role. As a report on Climate Change Performance Index results for 2014 has ranked KSA last at the list; similar to its previous year rank; it further senses positive signals from national strategy on climate change and energy which now in transition for change; country is in the most cooperative role for pre-COP negotiation processes since last 25 years. Moreover largest crude oil exporter of the globe is doing its preparations aggressively for a transition towards clean energy in coming 20 years by focusing on wind and solar power (Burck et al., 2014).

Many Saudi cities have started to suffer from Climate Change frequent flooding in Jeddah is evidence. A well groomed National policy framework is still awaited, to deal with threats of climate change directly, though it seems to be present in a fragmented manner in different sectorial policies (Darfaoui \& Al-Assiri, n.d).

We argue; policy gaps are more visible in Saudi cities where emphasis is mainly on the expansion of urban infrastructure while issues such as reduction in emission, research, database for proactive management, capacity building for disaster preparedness and building resilience for climate change is totally absent.

\subsection{Rapid Population Growth in Jeddah city}

Population growth is an important factor in estimating water demand. Rapid population growth leading to speedy urbanisation is the one of the important reason among others that is responsible for infrastructure deficit in the cities of developing countries. Climate change is adding more vulnerability in the capacities of intended services offered by existing urban infrastructure causing risks to its life cycle.

Similar to other Saudi cities population of Jeddah is rapidly growing; the population of city was hardly 1 million in 1980 which is reaching 3.4 million at present(Table-1). Researchers claimed variety of factors that are causing population growth, including rural-urban and urban-urban (from small cities) migration, international immigration, record growth in the local economy, amplified number of pilgrims, drastic drop in rate of mortality because of improvements in health amenities and doubtlessly the natural increase (Al-Hathloul \& Mughal, 1991; Abdu et al., 2002; Jeddah Municipality, 2004).

Table 1. Population growth in Jeddah

\begin{tabular}{cc}
\hline Year & $\begin{array}{c}\text { Population } \\
\text { in thousands }\end{array}$ \\
\hline 1980 & 927 \\
1990 & 1987 \\
2000 & 2528 \\
2010 & 3358 \\
2013 & 3480 \\
$2020 *$ & 4416 \\
$2030 *$ & 5747 \\
$2040 *$ & 7213 \\
\hline \multicolumn{2}{c}{$*$ Projection }
\end{tabular}

\subsection{Emission of Green House Gases-GHG in Jeddah City}

Ideally; Jeddah could be classified as Type 14 cities as per the taxonomy proposed by Saldivar-Sali (2010); which includes cities situated in oil producing economies. Total Material Consumption (TMC) in these cities is considerably higher because of their seamless wealth aided with lower bio-mass, industrial mineral and ore consumption which is due to lesser presence of industries that demands these inputs. The regional conditions in these cities are mostly arid and obviously energy consumption and $\mathrm{CO} 2$ emissions' level are high. Strategic Plan of Jeddah (2009) admits urgency of reduction in energy consumption aiming to decrease Jeddah's contribution to global GHG emission causing Climate Change though there is no concrete proposal or actions to execute it.

We observe that a high car ownership due to lack of convenient, reliable and acceptable public transportation 
system, cheap fossil fuel prices and water desalination plants with electric power cogeneration plants are the main source of GHG emission that was estimated $6.6 \mathrm{tCO} 2 \mathrm{e} / \mathrm{cap}$ recently that is far above in comparison to many cities such as Ahmedabad (1.2 tCO2e/cap), Bangalore (3.2 tCO2e/cap), Barcelona (4.2 tCO2e/cap), Belo Harizonto (3.6 tCO2e/cap), Bogota (3.4 tCO2e/cap), Brasilia (4.0 tCO2e/cap), Buenos Aires (3.8 tCO2e/cap), Cairo (3.8 tCO2e/cap), Kolakata (1.1 tCO2e/cap), Chennai (2.7 tCO2e/cap), Delhi (1.5 tCO2e/cap), Dhaka (0.6 tCO2e/cap), Ho Chi Minh (3.1 tCO2e/cap), Hyderabad (3.3 tCO2e/cap), Jakarta (3.3 tCO2e/cap), Karachi (2.0 tCO2e/cap), Khartoum (2.9 tCO2e/cap), Lagos (1.8 tCO2e/cap), Lima (2.6 tCO2e/cap), Medelin (5.1 tCO2e/cap), Mexico (2.8 tCO2e/cap), Mumbai (2.4 tCO2e/cap), Pune (4.5 tCO2e/cap), Rio-de-Janerio (2.1 tCO2e/cap), Salavador (3.8 tCO2e/cap), Santiago (4.3 tCO2e/cap), Sao-Paulo (1.4 tCO2e/cap), Seoul (4.1 tCO2e/cap), Tokyo (4.9 tCO2e/cap) as World Bank's data compendium on 100 largest cities divulges (Hoornweg, 2013).

Above data repository also reveals that up-to-date local agenda 21 and urban risk assessment mechanism is ambiguous in Jeddah city.

\subsection{Incidences of Urban Storm water Flooding in Jeddah}

The average annual rainfall received in Jeddah is only $25 \mathrm{~mm}$ (GPMEP, 2009); however the city has suffered twice from urban flooding in recent past last 5 years: Firstly on 25th November 2009 when city's many streets and squares were logged up to $270 \mathrm{~mm}$ of rainwater within 4 hours starting from morning 10 am to afternoon. Amount of the rainfall received during these hours was $90 \mathrm{mms}$ which was 260 percent more than usual annual rainfall(Al-Saud, 2009).City was repeatedly waterlogged again in 2011 with a rainfall of $110 \mathrm{mms}$ only in 3 hours; again it was exceeded by 330 percent than the usual annual rainfall (Davies, 2013). Both disasters caused death of around 133 people and damage to property was estimated 266 million USD; around 20 thousand families were forced to get shelter leaving their destroyed property; while legal trails are still continued; 21 people found guilty initially and sentenced to jail for 85 years with a penalty of 1733 million USD. These urban flood disasters forced policy makers to overhaul public policies dealing with natural disasters (Momani \& Fadil, 2010, Al-Sibyani, 2014).

In brief above reported extreme weather events exposed lack of institutional capacities to deal with climate related disasters at local level as well as deficiencies in the provision of urban water infrastructure.

\subsection{Roles That Desalination Plants Plays in Context to Future Climate Change}

Potable water supply in Jeddah is ensured through water desalination plants. These plants not only attracts higher capital and operating cost but also draws high amount of energy that causes excessive $\mathrm{CO} 2$ emissions due to burning of fossil fuels (Abazza,2012). These emissions could have far reaching consequences in the form of global warming leading to climate change and damaging urban infrastructures.

Desalination plants in Jeddah also generate electricity. Sommariva et al. (2010) estimated that footprint for power plants could be 0.5 to $0.8 \mathrm{Kg} \mathrm{CO}_{2} / \mathrm{kWh}$ which means annual emission from water desalination might be lesser if desalination plants are used for energy cogeneration.

At present Jeddah Business Unit-JBU of National Water Company-NWC supplies 1 million cubic meter of potable water every day while 6.09 kwn energy is usually required to desalinate 1 cubic meter amount of water. Based on this data we have calculated $\mathrm{CO}_{2}$ emission scenario from different sources of energy used (Table 2).

Table 2. Annual $\mathrm{CO}_{2}$ emissions estimation scenarios in Jeddah from water desalination plants*

\begin{tabular}{ccccccc}
\hline Energy sources & Coal & Oil & $\begin{array}{c}\text { Natural } \\
\text { gas }\end{array}$ & $\begin{array}{c}\text { Nuclear } \\
\text { energy }\end{array}$ & $\begin{array}{c}\text { Solar } \\
\text { power }\end{array}$ & $\begin{array}{c}\text { Wind } \\
\text { energy }\end{array}$ \\
\hline $\begin{array}{c}\text { Annual average } \mathrm{CO}_{2} \text { emission in } \\
\text { metric tons }\end{array}$ & 2001891 & 1378788 & 822890 & 6574 & 0 & 0 \\
\hline
\end{tabular}

*Based on Abazza, 2012

At present source of energy used for desalination plants in the city is petroleum oil that emits 1.37 million tons of $\mathrm{CO}_{2}$ annually, lesser than coal $(2 \mathrm{mt})$ but still higher than natural gas $(0.8 \mathrm{mt})$ and nuclear power $(.006 \mathrm{mt})$ sources while this emission can be totally vanished if solar or wind power sources are used. Desalination plants also have adverse impact on marine eco-systems from its thermal effect and also due to raised salt and chlorine levels in the return water (Beaumont, 2000). Officials of Jeddah Municipalities and experts indicated that city has a plan to transform its desalination plants towards clean energy though there is no strict timeline fixed for it. 


\subsection{Existing urban Water Infrastructure Scenario in Jeddah}

\subsubsection{Potable Water Supply}

The city is now efficient enough to fulfil entire water demand which was a dream in the last few decades. Studies reveals that only 50 percent potable water demand of the city was fulfilled until year 2001(Shawly, 2008) though at present there is no demand and supply gaps.

NWC sources confirms that current daily supply in Jeddah city is reaching at an average of 1 million cubic meters (ranging from 0.9 to 1.1 million cubic meters based on demands, out of which 90 percent is supplied through piped water supply distribution system. This supply is done from major sources: 640 thousand cubic meters from Shuaiba facility and rest 360 thousand cubic meters from City facility. Balance 10 percent of potable water supply (approximately 10 thousand cubic meters daily) is done with food grade tankers.

Apart from the government water supply there are private operators who distribute water by both pipelines and tankers.This supply is mainly for commercial purposes including the packaged water. SAWACO facilities in (i) Obhur North, (ii) Industrial City 2 and the (iii) Corniche; Kindasa,(iv) Water Services facility in the Jeddah Islamic Port; and (v) KAIA desalination plant serving the airport are among the private water distribution facilities. All private water facilities offer a daily supply of 100 thousand cubic meters.

A major problem by which city's water system are suffering is high amount of unaccounted for water (ufw). It was as high as 60 percent in past as JBU experts discloses and started to decline up to 30,20 and 10 at the most recent. In 2006 ufw was estimated by Al-Sefry and Şen, (2006) a daily of 190,000 cubic meters but at present rate of loss it could be approximately 110 thousand cubic meters of daily that is still higher. Most of this water loss is due to leakage and informal connections. Though JBU has strengthened its operation \& maintenance $(\mathrm{O} \& \mathrm{M})$ and minimized the ufw up to 10 percent of the supply or even lesser. Entering into PPP has paved way for the better operational efficiency as by now early detections has saved a huge volume of water for leakage for instance in 2008 NWC has saved only 7.2 cubic meter of water in this account which has increased up to 115.4 cubic meter in 2012.

We argue that climate change and population growth can aggravate the gap again in the future if the demand has not been properly predicted. For instance in year 2040 it has been estimated that city will need 2524 thousand cubic meters (Table 3) of potable water which prompts for an additional production of 1524 thousand cubic meters of water. Scenario could be even worse as we observed that per capita water consumption is constantly growing in the city as there is no stress on sustainable water consumption; experts claims that the water consumption will tend to rise also because of rise in temperatures.

Table 3. Potable water consumption and wastewater generation estimates

\begin{tabular}{ccc}
\hline Year & $\begin{array}{c}\text { Water } \\
\text { consumption } \\
\text { (in thousands } \\
\text { cubic meters) }\end{array}$ & $\begin{array}{c}\text { Wastewater } \\
\text { generation } \\
\text { (in thousands } \\
\text { cubic meters) }\end{array}$ \\
\hline 1980 & 156 & 134 \\
1990 & 377 & 321 \\
2000 & 500 & 445 \\
2010 & 940 & 806 \\
2013 & 1000 & 852 \\
$2020 *$ & $1325^{*}$ & $1149 *$ \\
$2030 *$ & $1850^{*}$ & $1610^{*}$ \\
$2040^{*}$ & $2524^{*}$ & $2100^{*}$ \\
\hline \multicolumn{3}{c}{ *projection }
\end{tabular}

\subsubsection{Water Tariffs}

International agencies considers cost recovery as a core element in the restructuring of water sector as studies 
indicates that there is enormous gap between cost recovery based on economic principles and the payments by water users who pays only a small portion of the real costs. In response water resource sector strategy of World Bank calls for ethical and realistic interventions and recommends developing a realistic and systematic approach to cost recovery (World Bank, 2004).

Cost recovery in urban water sector seems hard in KSA as it had unanimous flat water tariff across the regions. This tariff has changed into a progressive tariff since 1985 after governments' realization on financial and operating constraints (Shawly, 2008). Current tariffs are levied in 1994 (Table-4) argued to be promoting people's awareness on water conservation that proves wrong if we examine tariffs from other developed countries such as USA (1.25 USD), UK (2.28 USD), Australia (1.64 USD), Canada (0.70 USD), Portugal (1USD) and Netherlands (3.16 USD). All these countries have water tariff 15 to 80 times more than KSA (CWF, 2011).

In long run specially to tackle the risks of climate change; it will not be wise to keep water tariffs comparatively low. Tariffs must be revised based on economic principles of cost recovery so that climate change adaption projects could be financed in a sustainable way.

Table 4. Water tariff in Saudi Arabia

\begin{tabular}{ccc}
\hline Block & Units & $\begin{array}{c}\text { Per Unit Charge in } \\
\text { USD }(\$)\end{array}$ \\
\hline I & $1-50$ & 0.03 \\
II & $51-100$ & 0.04 \\
III & $101-200$ & 0.53 \\
IV & $201-300$ & 1.06 \\
V & More than 300 & 1.6 \\
\hline
\end{tabular}

\subsubsection{Wastewater Management}

Amounts of wastewater generated largely depend upon the potable water consumption and their reuses. The water supply in the city is not well supported by adequate sewer system while the city traditionally over relied upon septic tanks for the sanitation purposes which has created acute challenges for city's environmental health, among severe challenges are: pollution of groundwater storage through leakage of septic tanks mainly (currently Jeddah's groundwater is highly contaminated by nitrates hence useless either for drinking purposes or to support the expansion of green infrastructure in the city; another pressing challenge is overflow of existing sewer network because of unmanageable wastewater release from residential, industrial and institutional units.

Still a wide gap subsists between the amount of wastewater generated and capacities of its treatment. At household level 52.1 percent households are still not connected with sewer lines while this coverage is mainly at the central parts and some parts in the north (Figure 2 and Figure 3).By 2014 city's sewer treatment plants has installed capacities of 589 thousand cubic meters (Table 5) while wastewater generation accounted daily was more than 852 thousand cubic meters that shows only 62 percent capacity was available against the demand. Even further planning for the installation of wastewater treatment facilities is not enough Rest water either falls into Red Sea without any sort of treatment or sinking into groundwater storage having far reaching consequences, affecting marine eco-system, declining the quality of water used for desalination, waterlogging and overflows of sewer system in city and finally all these cumulatively creates negative impact on people's health. This scenario could be more worsen in extreme weather events (high rainfall) and sea level rise. 
Table 5. Installed and planned sewer treatment plant-STP capacities in Jeddah

\begin{tabular}{|c|c|c|}
\hline Location & Name & $\begin{array}{l}\text { Installed } \\
\text { capacity cubic } \\
\text { meters daily }\end{array}$ \\
\hline \multicolumn{3}{|l|}{ Installed } \\
\hline Al Khumrah & Phase 1 & 40 \\
\hline Al Khumrah & Phase 2 & 60 \\
\hline Al Khumrah & Phase 3 & 140 \\
\hline Jeddah City & Treatment Plant A & 32 \\
\hline Jeddah City & Treatment Plant $\mathrm{C}$ & 40 \\
\hline Jeddah City & Bani Malik & 8 \\
\hline Jeddah City & Al Escan & 11 \\
\hline Jeddah City & University & 8 \\
\hline Jeddah Airport & Phase 1 & 250 \\
\hline Total & & 589 \\
\hline \multicolumn{3}{|c|}{ Planned/Under Construction } \\
\hline Al Khumrah & Phase 4 & 250 \\
\hline Jeddah Airport & Phase 2 & 250 \\
\hline Jeddah Airport & Phase 3 & 250 \\
\hline Jeddah City & North & 150 \\
\hline Jeddah City & South & 60 \\
\hline Total & & 960 \\
\hline
\end{tabular}

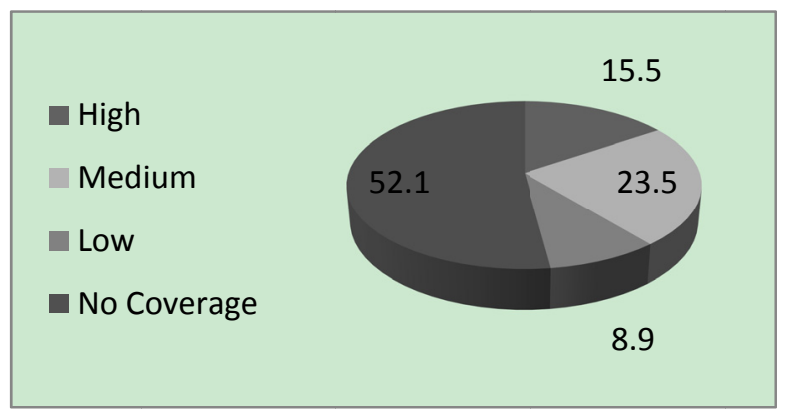

Figure 2. Coverage of sewer line connected households

\subsubsection{Storm Water Drainage}

The fact is not disputable that any alteration in the natural drainage in cities due to human activities can cause flood disasters. In case of Jeddah it was observed that historically construction of houses in the valleys was strictly prohibited; legitimacy was lost or forgotten in the later years and people started house construction in the valleys and other low-lying areas that blocked flow of storm rain water resultant; besides in past city was also well surrounded by canals which are now disappeared due to gigantic developments both has contributed into occurrence of severe floods.

Although the city has plan to expand its drainage network as higher drainage density can lower flood risks in extreme weather conditions, at present storm water drainage network is not adequate(Figure-3). At present average length of drainage in the city ranges from $.055 \mathrm{kms}$ to $0.097 \mathrm{kms}$ on average for each Square Kilometers of area; that could be considered as very low (Table 6). 
Table 6. Urban storm water drainage network in Jeddah

\begin{tabular}{lrrl}
\hline Drainage Channel & Length $(\mathrm{Km})$ & Density $\left(\mathrm{Km} / \mathrm{Km}^{2}\right)$ & Remark \\
\hline Eastern & 21.1 & 0.055 & Very Low \\
Western & 29.74 & 0.077 & Very Low \\
Southern & 37.4 & 0.097 & Very Low \\
\hline Total & 88.24 & & \\
\hline
\end{tabular}

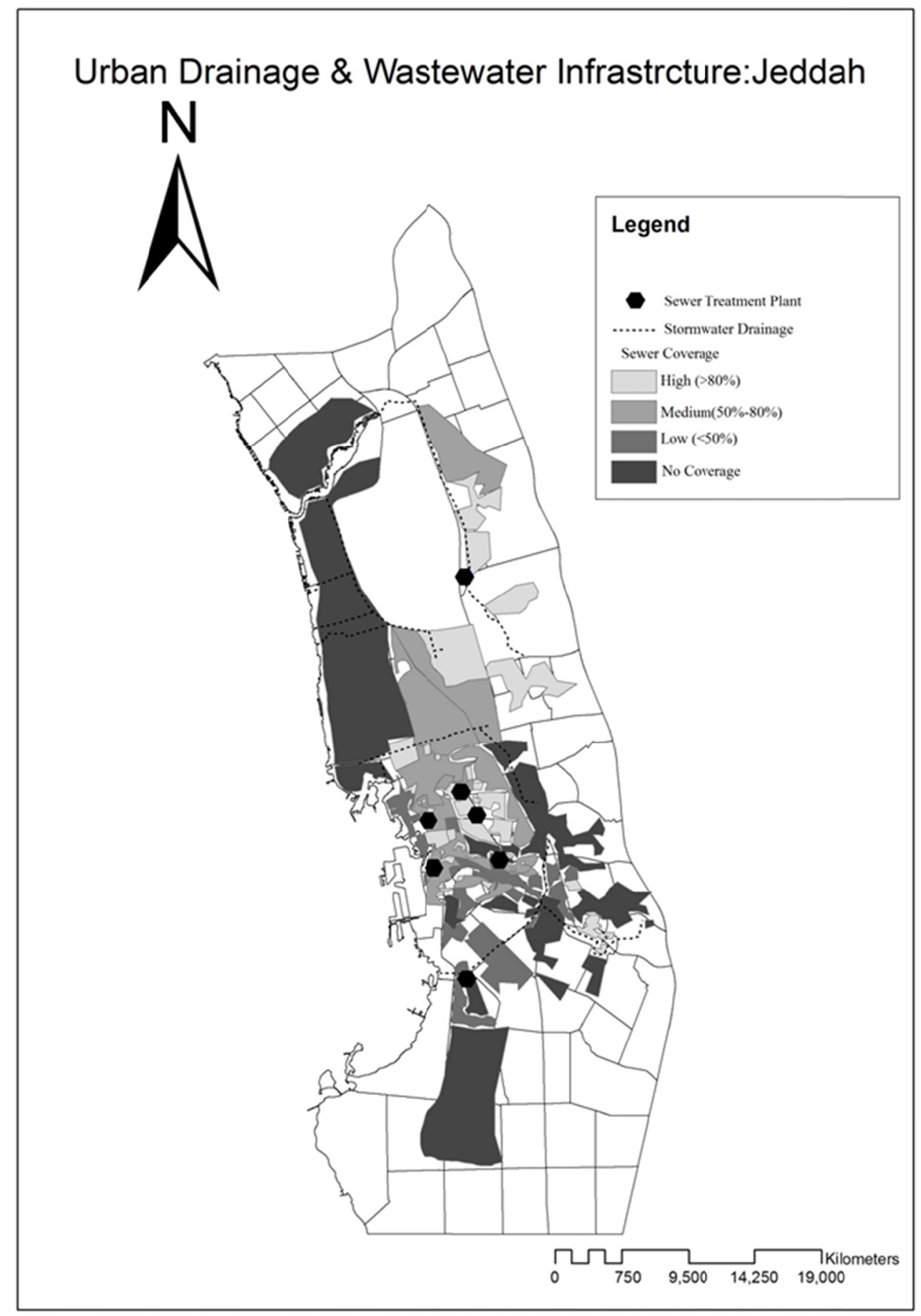

Figure 3. Urban drainage and storm water network infrastructure in Jeddah 


\subsubsection{Urban Groundwater Rising Problems and Its Pollution}

Jeddah is a city characterised by a coastal semi-arid climatic conditions, urban growth, expansion and population growth has stressed urban water supply as its natural hydrological cycle proved insufficient to fulfil growing water demands. Mounting capacities from external hydrological cycle (Water supply from Desalination of Red Sea water) on one hand calmed the city's water demand but on other hand it has started to disrupt natural hydrological cycle in the city. It has happened especially because the supporting wastewater and storm water infrastructure was not adequately provisioned. This provisional gap has increased seepage of wastewater into groundwater storage which is sometimes also mixed with leakages from septic tanks; all this has resultant into excessive pollution (due to nitrates) of groundwater and rising of groundwater table in the city.Most recently researchers have estimated that the groundwater table in the city is rising annually by 10 centimetres while there is no sustainable remedy; to cope up with this challenge (Al-Sefry \& Şen, 2006; Haddadin, 2002).

Rising groundwater water table in Jeddah city might prove a greater threat to the buildings because of its chemical content but also many other infrastructure like transportation, storm water drainage and sewage (Abderrahman, 2000; Vincent, 2003).Adverse impact of Climate change can be more worsen with groundwater problems that can even put question mark on the existence of this coastal city.

Because of excessive pollution city's groundwater is no longer in use either for drinking or irrigational purpose.

We argue that if the problems of groundwater pollution and its rising are not sustainably tackled it can create a threat on city's existence clubbed with sea-level rise.

It can be concluded from previous discussions that entire flow of urban water in Jeddah is not sustainable and supporting infrastructures are not even adequate that hampers city's resilience towards climate change (Figure 4).

Jeddah: Complexity of Urban Water flow in relation to Climate Change

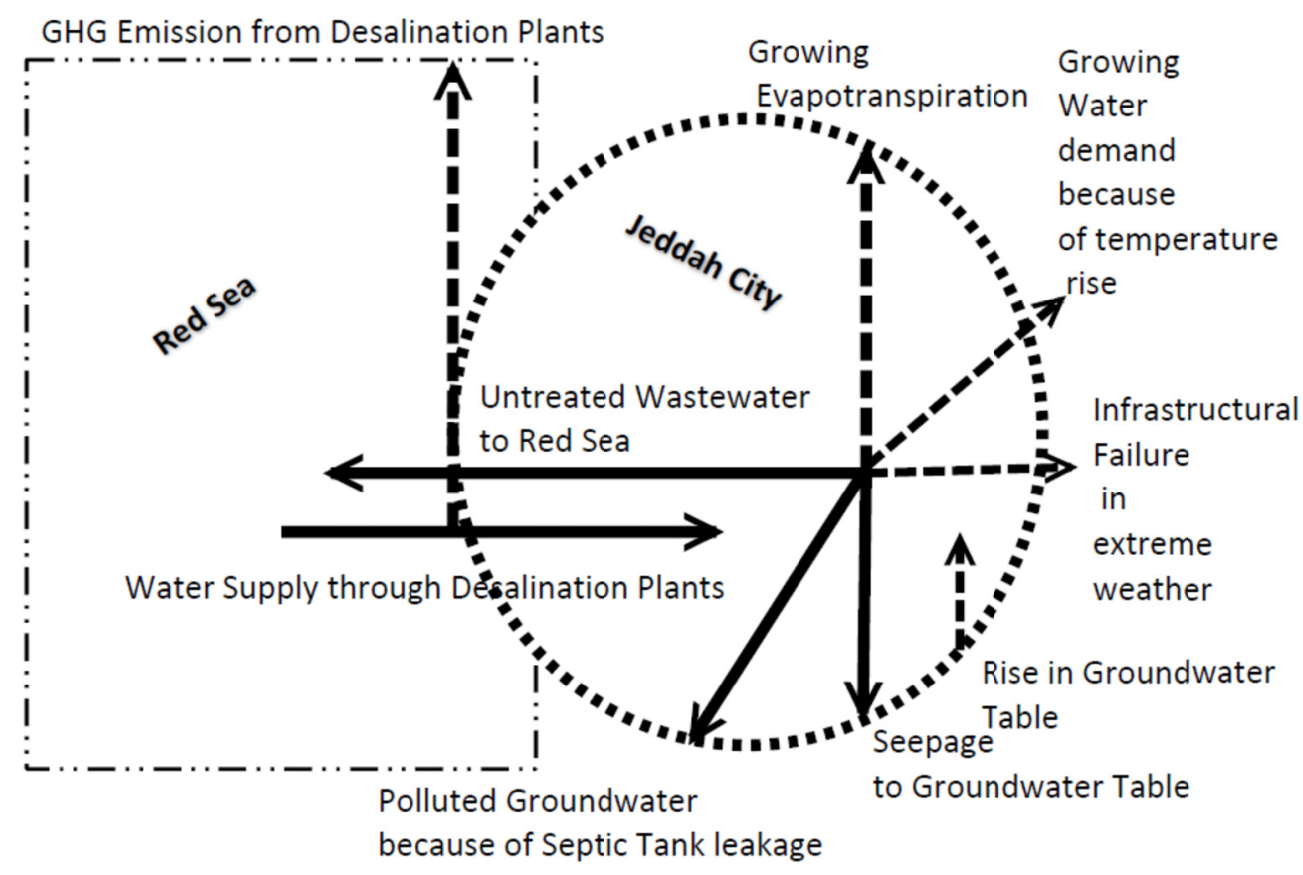

Figure 4.

\section{Policy Level Preparedness Assessment for Climate Change Adaption in Jeddah}

We have carried a qualitative assessment of preparedness for climate change adaption policies for urban water infrastructure in Jeddah (Table 7) and the findings were as following:

(i) A city level climate change adaption strategy is absent either in general scenario or specifically for urban water infrastructure.

(ii) We found urban water infrastructure plan and design is in a medium state of resilience as city have an integrated water and wastewater master plan though it still planned to deliver services with huge 
centralised networks that are often criticised because of their inability in absorbing natural disasters (Swilling and Annecke 2012).

(iii) We observed that facilities for urban water capture and storage is also medium.

(iv) In absence of robust policies water and wastewater reuse is low.

(v) Storm water management and flood control mechanism is at medium level.

(vi) While urban agriculture is totally absent, urban greening is only at less than $1 \mathrm{sq} \mathrm{km}$ of area and considered as low.

(vii)Experts expressed that level of institutional capacities in climate change adaptions is low.

(viii) Lack of proper data and information required for climate change adaption strategy is a major hurdle at policy formulation; hence recognised as low level.

(ix) Although there is an early warning system from civil defense to alert people through SMS and other modes of media; but still level public education and outreach on climate change issue is low.

(x) Research on climate change issues are being carried out in a fragmented manner that indicates its low level, current researches are mainly focused on proving climate change not on the developing of adaption mechanism.

(xi) Process of technology development for climate change adaption is medium and predominantly relies on imported ideas whose success is not proved.

Table 7. Adaption for climate change: A policy matrix for urban water infrastructure

\begin{tabular}{|l|l|l|l|l|l|}
\hline Sl. & Adaption Element & Absent & Low & Medium & High \\
\hline 1 & City level climate change adaption strategy & & & & \\
\hline 2 & Urban water infrastructure plan and design & & & & \\
\hline 3 & Urban water capture and storage & & & & \\
\hline 4 & Water and waste water reuse & & & & \\
\hline 5 & Storm water management and flood control & & & & \\
\hline 6 & Urban agriculture and urban greening & & & & \\
\hline 7 & Institutional capacity & & & & \\
\hline 8 & Data and information & & & & \\
\hline 9 & Public education and outreach & & & & \\
\hline 10 & Research & & & & \\
\hline 11 & Technology development & & & & \\
\hline
\end{tabular}

We propose that above matrix enriched with refined data can act as base for the preparation of an integrated climate change adaption strategy for urban water infrastructure resilience in Jeddah.

\section{Recommendations for Climate Change Adaption in Urban Water Infrastructure Sector}

We propose a 3 point strategy for climate change adaption in urban water infrastructure sector as following:

\subsection{Expansion and Reconfiguration of Hard Infrastructures}

The first step towards climate change resilience could be expansion and reconfiguration of urban water infrastructure in an integrated manner. Here expansion is related to full geographical coverage of urban water supply, storm water drainage and sewage infrastructure, while reconfiguration is adjusting existing infrastructure to make them resilient and robust for climate change. Upgrading and raising the drainage system has greater importance. While doing so various interconnections of urban water infrastructures should be taken care of (Figure 5). 


\section{Climate Change and Urban Water Infrastructure Interconnections}

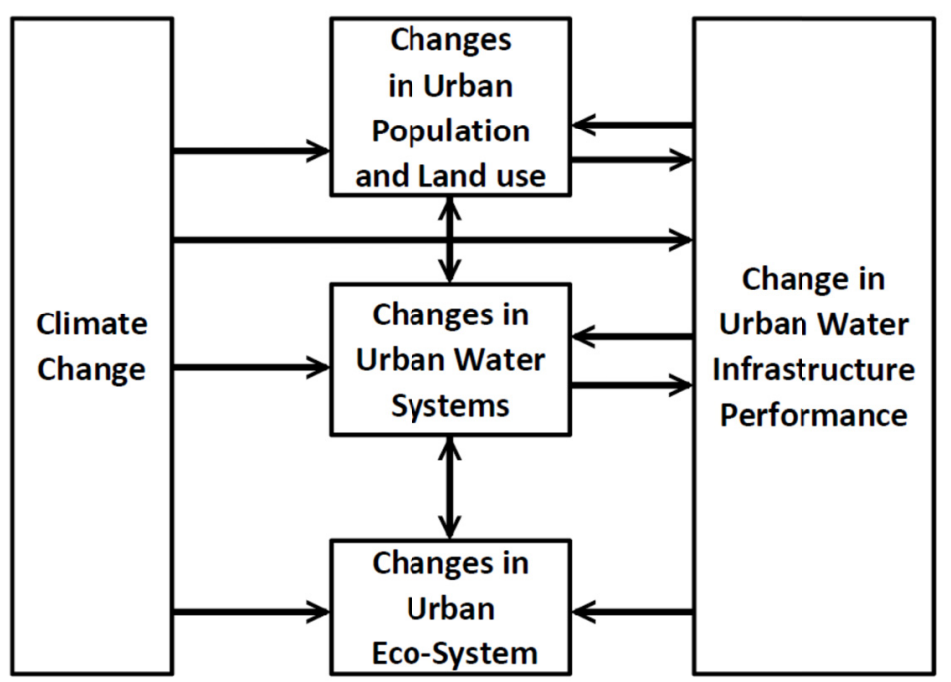

Figure 5.

NWC sources reveal that full provision of integrated urban water infrastructure for Jeddah city will cost 4 Billion USD by year 2017. This investment will be required for many components including water plants, wells and reservoirs, water mains, water networks, household water connections. Policy makers has well realised that this huge investment and its execution and management is not solely possible by the government hence privatisation of water infrastructure has emerged as a solution especially when the tariffs of such facilities are extremely low in government regimes.

\subsection{Remediating Climate Change with Green Infrastructure}

Green infrastructures have been recognised as an 'ecosystem-based adaption (EbA) approach to climate change adaption in recent years (Jones et al., 2012); especially in the cities located in arid and semi-arid regions where water availability is sacred (Maimaitiyiming et al., 2014). Green Infrastructure offers multiple co-benefits when blended with grey infrastructure (engineering or hard infrastructures) particularly in the retention and detention of storm water and wastewater (Gaffin et al., 2012). Many cities of the world have developed their own planning framework after realising value of Green infrastructures such as Water Sensitive Urban Design (WSUD) in Australian city Melbourne based on certain key principles such as protecting urban waterways, managing storm water in the landscape and adding multiple benefits while minimising development costs (MW, n. d.). Importance of WSUD has been accepted in UK also as a method of assimilating management of water cycle in the built environment through urban planning and urban design in which green infrastructure plays a vital role (CIRIA, 2013). Unfortunately on one hand existing green infrastructure coverage in Jeddah is spread hardly over one percent of geographical area (Khalili, 2014).

Therefore, urban policymakers in Jeddah must recognise the climate change adaption values of Green Infrastructure by integrating in the city level climate change adaption strategies.

\subsection{Climate Change Adaption through Soft Infrastructure Investments}

Soft infrastructures are essential component to climate change adaptions such as urban designing and planning, awareness creation, capacity building, technological advancement, research and development. In context of Jeddah urban planners and designers should aim at restraining population growth in coastal areas and also attempt to redistribute residential areas to comparatively higher elevations to avoid any future threats because of sea level rise. Water flows in upstream reservoirs should also be valued by constant monitoring of surface run-off. Research and Development should be emphasised for the prediction of short and long term water flows. Selection of appropriate technologies and building capacities and raising public education are indispensable elements of climate change adaption strategies.

Scholars indicated climate change adaption policies could be a sustainable driver for knowledge based economy though these actions calls for many more actions such as water tariff reforms, water conservation and integrated management of water resources. Research and Development for Solar powered desalination and water demand 
management should also be amalgamated in targeted adaptions (Bushnak, 2010).

\section{Conclusion}

Urban water supply in Jeddah relies upon desalination plants that emit a larger amount of green house gases-GHG and heat that have negative impacts on urban eco-system and marine eco-system as well. Higher levels of emission from these plants are mainly because of the fossil fuel used in it; uses of clean energy sources (solar, wind) can minimise the problem but higher energy subsidies on fossil fuels are obstructing this transformation. Unaccounted of water is still high due to operational deficiencies, sewer network and storm water drainage is not adequate in the city while the water tariffs are extremely low in comparison to many other countries. Less reuse of water and treated wastewater is reducing efficiency of water resources. Apparently rise in ground water table is put city's existence at risk. We conclude that urban water infrastructure scenario in Jeddah is not fairly resilient for future climate change. Even the climate change adaption policies are either poor or absent at different level. Hence, climate change is a wakeup call for the stakeholders engaged directly or indirectly in urban water infrastructure planning, financing, provision, management, operation, maintenance and governance. Climate change is now indubitable, which attracts urgent actions as any further delay can worsen anticipated risks, even it can increase the cost of adaption. UN Secretary General has warned global community by saying: More we delay the More we will pay (Ban-kimoon, 2014). A three point strategy has been proposed to adapt climate change in urban water infrastructure that includes: investing in hard infrastructure, green infrastructure and soft infrastructure. Active partnerships among government, private sector and people will strengthen such adaption strategies.

\section{References}

Abazza, H. (2012). Economic Considerations for Supplying Water Through Desalination in South Mediterranean Countries, Report of EU Funded Project, SWIM. Retrieved from http://www.swim-sm.eu/files/Economic_Considerations_on_Desalination_Final.pdf

Abderrahman, W. A. (2000). Urban water management in developing arid countries. Int. J. Water Resour. Dev., 16, 7-20. http://dx.doi.org/10.1080/07900620048536

Abdu, M., Salagoor, J., \& Al-Harigi, F. (2002). Jeddah urban growth and development process: The underlying factors. Scientific Journal of King Faisal University: Basic and Applied Sciences, 3(1), 111-136.

Al-Hathloul, S., \& Mughal, M. (1991). Jeddah. Cities, 8(4), 267-273. http://dx.doi.org/10.1016/0264-2751(91)90042-P

Almazroui, M., Islam, M. N., Jones, P. D., \& Athar, H. (2012). Recent climate change in the Arabian Península: Seasonal rainfall and temperature climatology of Saudi Arabia for 1979-2009. Atmospheric Research, 111, 29-45. http://dx.doi.org/10.1016/j.atmosres.2012.02.013

Al-Saud, M. (2010). Assessment of Flood Hazard of Jeddah Area 2009, Saudi Arabia. Journal of Water Resource and Protection, 2, 839-847. http://dx.doi.org/10.4236/jwarp.2010.29099

Al-Sefry, A. S., \& Şen, Z. (2006). Groundwater Rise Problem and Risk Evaluation in Major Cities of Arid Lands - Jedddah Case in Kingdom of Saudi Arabia. Water Resources Management, 20(6), 91-108. http://dx.doi.org/10.1007/s11269-006-4636-2

Al-Sibyani, K. (2014). 21 jailed in Jeddah floods case, Arab News, 27 March 2013. Retrieved from http://www.arabnews.com/saudi-arabia/21-jailed-jeddah-floods-case

Beaumont, P. (2000). The quest for water efficiency-restructuring of water use in the Middle East. Water Air Soil Pollution, 123, 551-564. http://dx.doi.org/10.1023/A:1005225302371

Bruijn, J. A. D., \& Herder, P. M. (2009). System and actor perspectives on sociotechnical systems IEEE Trans. Syst. Man. Cybern. Part A Syst. Hum., 39(2), 981-992. http://dx.doi.org/10.1109/TSMCA.2009.2025452

Burck, J., Marten, F., \& Bals, C. (2014). The Climate Change Performance Index Results 2014, German Watch \& Climate Action Network. Retrieved from https://germanwatch.org/en/download/8599.pdf

Bushnak, A. A. (2010). Desalination. In M. El-shry, N. Saab, \& B. Zeitoon (Eds.), Arab Environment: Water Sustainable Management of a Scarce Resource, Report of AFED. Lebanon. Retrieved from http://www.afedonline.org/Report2010/pdf/En/Chapter8.pdf

Chappin, E. L. J., \& Lei, T. V. D. (2014). Adaptation of interconnected infrastructures to climate change: A socio-technical systems perspective. Utilities Policy, 31, 10-17. http://dx.doi.org/10.1016/j.jup.2014.07.003

CIRIA. (2013). Water sensitive urban design in the UK, Ideas for Built environment Practitioners. London. Retrieved

December

22 ,

2014,

from 
http://www.susdrain.org/files/resources/ciria_guidance/wsud_ideas_book.pdf

Cubasch, U. et al. (2001). Projections of future climate change. Climate change 2001: The scientific basis. In J. T. Houghton, et al. (Eds.), Contribution of Working Group I to the Third Assessment Report of the Intergovernmental Panel on Climate Change (pp. 525-582). Cambridge University Press, Cambridge, U.K..

CWF-Canada West Foundation. (2011). Water Pricing, Canada Water Pricing Backgrounder. Retrieved from http://cwf.ca/pdfdocs/publications/Water_Backgrounder_8_Sept_2011.pdf

Darfaoui, E. M., \& Al-Assiri, A. (n. d.). Responses to Climate Change in the Kingdom of Saudi Arabia, A report prepared for FAO-RNE.

Davies, R. (2013). Jeddah Flood Defenses, Flood List. Retrieved July 29, 2013, from http://floodlist.com/asia/jeddah-flood-defences

Davis, S. J., \& Caldeira, K. (2010). Consumption-based accounting of $\mathrm{CO}_{2}$ emissions. Proceedings of the National Academy of Sciences, 107(12), 5687-5692. http://dx.doi.org/10.1073/pnas.0906974107

Dodman, D. (2009). Blaming cities for climate change? An analysis of urban greenhouse gas emissions inventories. Environment and Urbanization, 21(1), 185-201. http://dx.doi.org/10.1177/0956247809103016

Gaffin, S. R., Rosenzweig, C., \& Kong, A. Y. Y. (2012). Adapting to climate change through urban green infrastructure. Nature Climate Change, 2, 704. http://dx.doi.org/10.1038/nclimate1685

GPMEP. (2009). General Presidency of Metrology and Environmental Protection, Database on Rainfall.

Haddadin, M. J. (2003). Water issues in the Middle East challenges and opportunities. Water Policy, 4(3), 205-222. http://dx.doi.org/10.1016/S1366-7017(02)00028-4

Hoornweg, D. (2013). A Data Compendium for the World's 100 Largest Urban. Retrieved November 27, 2014, from https://openknowledge.worldbank.org/bitstream/handle/10986/18666/801060WP0v20100Box0379805 B00PUBLIC0.pdf?sequence $=1$

IPCC. (2006). Overview. In Intergovernmental Panel on Climate Change Guidelines for National Greenhouse Gas Inventories (pp. 1-12). Japan: IPCC. Retrieved from http://www.ipcc-nggip.iges.or.jp/public/2006gl/

IPCC. (2007). Impacts, Adaptation and Vulnerability. In M. L. Parry, et al. (Eds.), Intergovernmental Panel on Climate Change. Cambridge: UK.

Jeddah Municipality. (2004). Jeddah structure plan, Jeddah Municipality, Saudi Arabia.

Jones, H. P., Hole, D. G., \& Zavaleta, E. S. (2012). Harnessing nature to help people adapt to climate change. Nature Climate Change, 2, 504-509. http://dx.doi.org/10.1038/nclimate1463

Khalil, R. (2014). Quantitative evaluation of distribution and accessibility of urban green spaces -Case study: City of Jeddah. International Journal of Geomatics and Geosciences, 4(3), 526-535.

Klein, R. J. T., Schipper, E. L., \& Dessai, S. (2003). Integrating mitigation and adaptation into climate and development policy: three research questions, Working Paper 40, Tyndall Centre for Climate Change Research, UK.

Lahn, G., \& Stevens, P. (2011). Burning Oil to Keep Cool, The Hidden Energy Crisis in Saudi Arabia. Chatham House, London.

Maimaitiyiming, M., Ghulam, A., Tiyip, T., Pla, F., Latorre-Carmona, P., Halik, U., Sawut, M., \& Caetano M. (2014). Effects of green space spatial pattern on land surface temperature: Implications for sustainable urban planning and climate change adaptation. ISPRS Journal of Photogrammetry and Remote Sensing, 89, 59-66. http://dx.doi.org/10.1016/j.isprsjprs.2013.12.010

Miles, S., \& Miles, M. (2004). Consuming Cities. Palgrave Macmillan: NY.

Minx, J. C., Baiocchi, G., Wiedmann, T., Barrett, J., Creutzig, F., Feng, K., Förster, M., Pichler, P.-P., Weisz, H., \& Hubacek, K. (2013). Carbon footprints of cities and other human settlements in the UK. Environmental Research Letters, 8(3), 35-39. http://dx.doi.org/10.1088/1748-9326/8/3/035039

Momani, N. M., \& Fadil, A. S. (2010). Changing Public Policy Due to Saudi City of Jeddah Flood Disaster. Journal of Social Sciences, 6(3), 424-428. http://dx.doi.org/10.3844/jssp.2010.424.428

MW-Melbourne Water. (n. d.). Water Sensitive Urban Design. Retrieved November 22, 2014, from http://www.melbournewater.com.au/wsud

OECD. (2014). Cities and Climate Change -Policy Perspectives: National governments enabling local action, OECD, Paris.

Pageler, M. (2011). Local government perspective on adapting water management to climate change. Retrieved 
from http://www.worldwatercouncil.org/fileadmin/world_water_council/documents_old/Library/Publica tions_and_reports/Climate_Change/PersPap_14._WASH_Services_Delivery.pdf

Randers, J. (2012). 2052: A Global Forecast for the Next Forty Years. White River Junction, VT, Chelsea Green Publishing.

Reusser, D. E., Lissner, T. K., Pradhan, P., Holsten, A., Rybski, D., \& Kropp, J. P. (2013). Relating climate compatible development and human livelihood. Energy Procedia, 40, 192-201. http://dx.doi.org/10.1016/j.egypro.2013.08.023

Saldivar-Sali, A. N. D. (2010). A Global Typology of Cities: Classification Tree Analysis or Urban Resource Consumption. Thesis submitted in partial fulfilment of the requirements of a Master of Science in Building Technology, Department of Architecture, Massachusetts Institute of Technology, USA.

Schweikert, A., Chinowsky, P., Espinet, X., \& Tarbert, M. (2014). Climate Change and Infrastructure Impacts: Comparing the Impact on Roads in ten Countries through 2100. Procedia Engineering, 78, 306-316. http://dx.doi.org/10.1016/j.proeng.2014.07.072

Selvaraju, R. L. R. (2013). Implications of Climate Change for Agriculture and Food Security in the Western Asia and Northern Africa Region. In V. K. Mannava, V. K. M. Sivakumar, R. L. R. Selvaraju, \& I. Hamdan (Eds.), Climate Change and Food Security in West Asia and North Africa. Springer. http://dx.doi.org/10.1007/978-94-007-6751-5_2

Sharp, E. B. (2011). Understanding Local Adaption and Implementation of Climate Change Mitigation Policy. Urban Affairs Review, 47(3), 433-457. http://dx.doi.org/10.1177/1078087410392348

Shawly, H. H. (2008). Urban Water: Integrated Resource Planning to Meet Future Demand in Jeddah - Saudi Arabia (Stuttgart Reports on Waste Management), DIG, pp. 118-119.

Swilling, M., \& Annecke, E. (2012). Just Transitions: Explorations of Sustainability in an Unfair World. Cape Town and Tokyo: UCT Press and United Nations University Press.

Swilling, M., Robinson, B., Marvin, S., \& Hodgson, M. (2012). Reshaping urban infrastructure: material flow analysis and transitions analysis in an urban context. Journal of Industrial Ecology, 16(6), 789-800. http://dx.doi.org/10.1111/j.1530-9290.2012.00559.x

UN. (2014). The more we delay, the more we will pay, 'says Ban, urging action on climate. Retrieved December 11, 2014, from http://www.un.org/apps/news/story.asp?NewsID=49583\#.VJ5qu14AgA

UNEP. (2013). City-Level Decoupling: Urban resource flows and the governance of infrastructure transitions. A Report of the Working Group on Cities of the International Resource Panel. Swilling M., Robinson B., Marvin S. and Hodson M., UNEP, Nairobi.

UNEP. (2014). Climate Change Threatens Irreversible and Dangerous Impacts, But Options Exist to Limit its Effects. $\quad$ Retrieved from http://www.unep.org/Documents.Multilingual/Default.asp?DocumentID=2812\&ArticleID=11035\&l=en

Van Vliet, M. T. H., Yearsley, J. R., Ludwig, F., Vgele, S., Lettenmaier, D. P., \& Kabat, P. (2012). Vulnerability of US and European electricity supply to climate change. National Climate Change, 2(9), 676-681. http://dx.doi.org/10.1038/nclimate1546

Vidal, J. (2010). Saudi Arabia to seek compensation for climate pact oil losses, The Guardian. Retrieved from http://www.theguardian.com/environment/2010/aug/04/saudi-arabia-climate-change-compensation

Vincent, P. (2003). Jeddah's Environmental Problems. Geographical Review, 93(3), 394-412.

World Bank. (2004). Cost Recovery for Water Supply for Water Supply and Sanitation and Irrigation and Drainage Projects. $\quad$ Retrieved November 30, 2014, from http://water.worldbank.org/sites/water.worldbank.org/files/publication/costrecovery.pdf

Zhou, B., Rybski, D., \& Kropp, J. (2013). The statistics of urban heat island intensity. Geophysical Research Letters, $40(20), \quad 5486-5491$. Retrieved November 22, 2014, from http://doi.wiley.com/10.1002/2013GL057320

\section{Copyrights}

Copyright for this article is retained by the author(s), with first publication rights granted to the journal.

This is an open-access article distributed under the terms and conditions of the Creative Commons Attribution license (http://creativecommons.org/licenses/by/3.0/). 